\title{
PEMANFAATAN BIOGAS SEBAGAI SUMBER ALTERNATIF TENAGA LISTRIK DI BBPTU HPT BATURRADEN
}

\author{
Gema Romadhona ${ }^{1}$, Winarso ${ }^{2}$, Akhmad Mukholik ${ }^{3}$ \\ ${ }^{1}$ Program Studi D4 Teknik Rekayasa Elektromedis, Fakultas Ilmu Kesehatan, Universitas Muhammadiyah Purwokerto \\ ${ }^{2,3}$ Program Studi S1 Teknik Elektro, Fakultas Teknik dan Sains, Universitas Muhammadiyah Purwokerto
}

\begin{tabular}{l}
\hline Informasi Makalah \\
\hline Dikirim, 01 Maret 2020 \\
Direvisi, 17 April 2020 \\
Diterima, 20 April 2020 \\
\hline
\end{tabular}

\section{Kata Kunci:}

Coal

Biogas

Friesian Holstein

\begin{abstract}
INTISARI
Kebutuhan energi listrik setiap tahun selalu meningkat, sedangkan cadangan sumber energi listrik yang tidak dapat diperbaharui semakin menipis dan akan habis seperti batubara, minyak bumi, dan gas alam. Pembakaran langsung batubara akan dihasilkan gas $\mathrm{CO}_{2}$ yang menimbulkan pencemaran udara, serta polutan radioaktif yang dapat meningkatkan paparan radioaktivitas alam. Oleh karena itu perlu adanya kreatifitas dalam menggunakan sumber daya alam untuk menghasilkan listrik yang ramah lingkungan serta dapat dipebaharui. Pada penelitian ini, peneliti meneliti biogas yang berasal dari feses Sapi Perah jenis FH (Friesian Holstein). Biogas ini memiliki banyak keunggulan yaitu dapat diperbaharui, mengurangi pencemaran udara, emisi gas rumah kaca, dan pemanasan global, karena gas metan $\left(\mathrm{CH}_{4}\right)$ yang dihasilkan dari feses Sapi masuk ke degester kemudian dimanfaatkan untuk membangkitkan energi listrik. Parameter yang diukur adalah berapa besar energi listrik yang dapat dihasilkan dari feses Sapi. Dalam sehari dengan jumlah 232 Sapi menghasilkan feses basah $6.960 \mathrm{~kg}$, digunakan untuk biogas terbentuk $125,28 \mathrm{~m}^{3}$ biogas yang dapat menghasilkan 8070,12 Watt. Energi listrik yang dihasilkan masih hanya digunakan untuk penerangan.
\end{abstract}

\section{ABSTRACT}

The need for electricity every year is always increasing, while reserves of non-renewable sources of electrical energy are running low and will run out, such as coal, petroleum, and natural gas. Direct combustion of coal will produce $\mathrm{CO}_{2}$ gas which causes air pollution, as well as radioactive pollutants that can increase exposure to natural radioactivity. Therefore there is a need for creativity in using natural resources to produce electricity that is environmentally friendly and renewable. In this study, researchers examined biogas derived from dairy cow feces type FH (Friesian Holstein). Biogas has many advantages that can be renewed, reduce air pollution, greenhouse gas emissions, and global warming, because methane $\left(\mathrm{CH}_{4}\right)$ produced from cow feces into the degester and then used to generate electricity. The measured parameter is how much electrical energy can be produced from cow feces. In a day with a total of 232 cows produce $6,960 \mathrm{~kg}$ of wet feces, used for biogas formed $125.28 \mathrm{~m} 3$ of biogas which can produce 8070.12 Watt. The electricity generated is still only used for lighting.

\section{Korespondensi Penulis:}

Gema Romadhona

Program Studi Teknik Rekayasa Elektromedis

Universitas Muhammadiyah Purwokerto

Jl. Letjen. Soepardjo Roestam Km. 7 PO. BOX 229 Purwokerto 53181

Email: gema.romadhona@gmail.com 


\section{PENDAHULUAN}

Energi listrik sudah menjadi kebuhan pokok di zaman sekarang. Kebutuhan energi listrik setiap tahun selalu meningkat, sedangkan cadangan sumber energi listrik yang tidak dapat diperbaharui/akan habis seperti batubara, minyak bumi, dan gas alam semakin menipis. Disamping itu pembakaran langsung batubara akan dihasilkan gas $\mathrm{CO}_{2}$ yang dapat menimbulkan pencemaran udara, serta polutan radioaktif yang dapat meningkatkan paparan radioaktivitas alam. Radionuklida alam yang terkandung dalam batubara berupa kalium, uranium, thorium, dan produk- produk peluruhannya [1]. Oleh karena itu perlu adanya kreatifitas dalam menggunakan sumber daya alam untuk menghasilkan listrik yang ramah lingkungan serta yang dapat dipebaharui.

Biogas merupakan gas yang dihasilkan oleh aktivitas anaerobik atau fermentasi dari bahan-bahan organik termasuk diantaranya kotoran manusia dan hewan, limbah domestik (rumah tangga), sampah biodegradable atau setiap limbah organik yang biodegradable (senyawa yang mudah diuraikan oleh mikroorganisme) dalam kondisi anaerobik [2]. Biogas dapat digunakan untuk bahan bakar motor/genset. Biogas memiliki banyak keunggulan yaitu dapat diperbaharui, mengurangi pencemaran udara, emisi gas rumah kaca, dan pemanasan global, karena gas metan $\left(\mathrm{CH}_{4}\right)$ yang dihasilkan dari feses Sapi masuk ke degester kemudian dimanfaatkan untuk membangkitkan energi listrik.

Pada penelitian ini yang digunakan untuk membuat biogas adalah dari feses/kotoran hewan yaitu Sapi Perah jenis FH (Friesien Holstein) yang berada di BBPTU HPT Baturraden Kabupaten Banyumas Provinsi Jawa Tengah. Peneliti memilih di lokasi ini karena jumlah sapi yang terus ada keberadaannya dan dalam jumlah yang banyak.

\section{METODOLOGI PENELITIAN}

\subsection{Alur Penelitian}

Berikut alur penelitian dalam penelitian ini

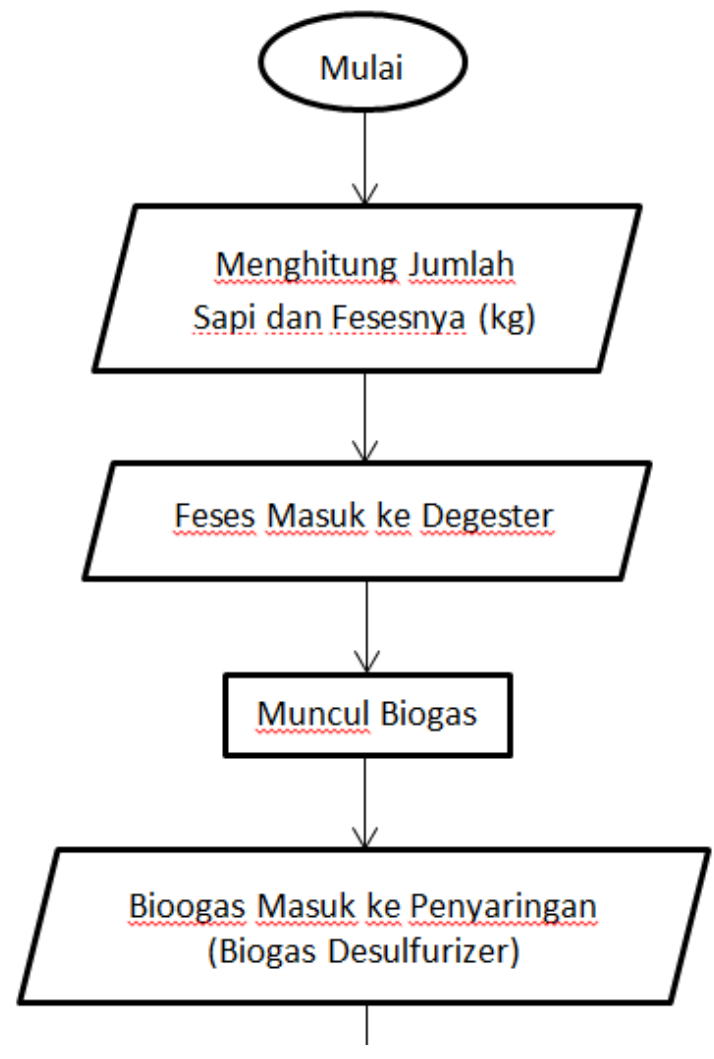




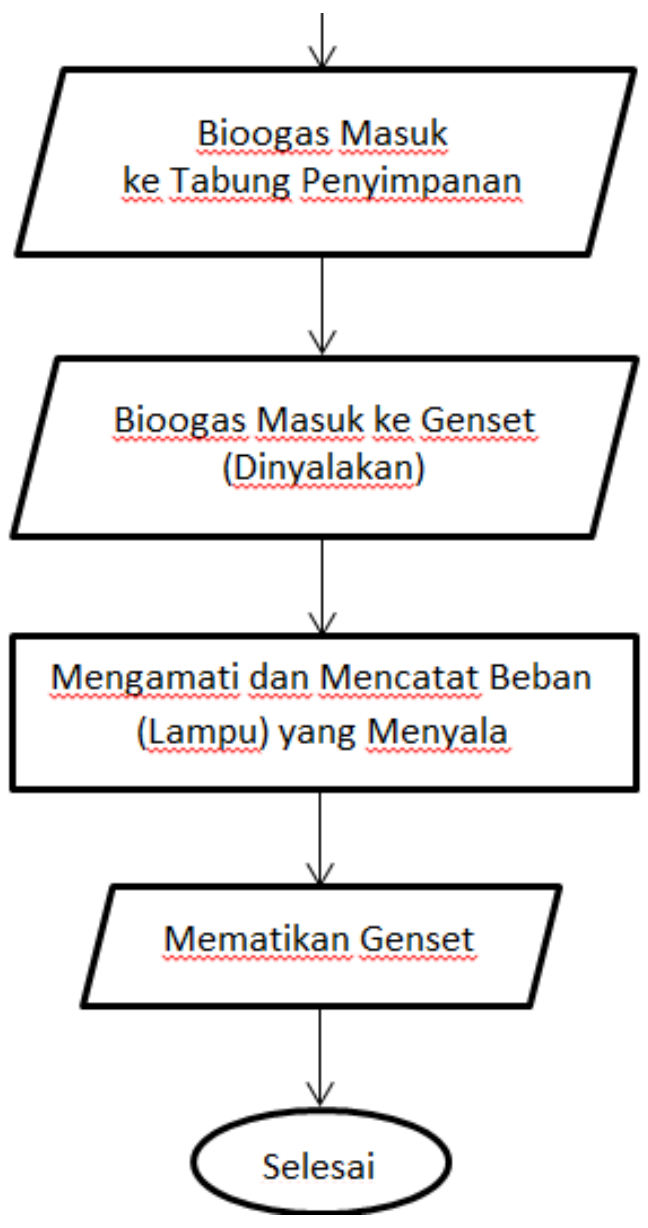

\subsection{Lokasi Penelitian}

Lokasi penelitian berada di BBPTU HPT Area Farm Limpakuwus, tepatnya di Dusun III, Limpakuwus, Kec. Sumbang, Kabupaten Banyumas, Jawa Tengah 53183

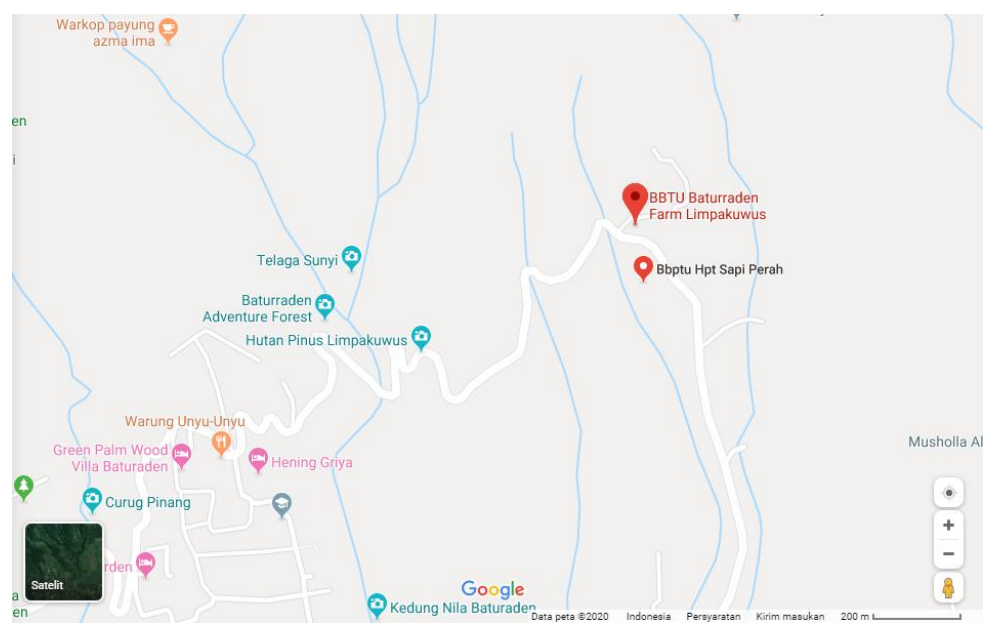

Gambar 2. Lokasi BBPTU HPT Baturraden Area Farm Limpakuwus

Sumber : https://www.google.com/maps/place/BBTU+Baturraden+Farm+Limpakuwus/@ _

7.3062261,109.2409754,16z/data=!4m12!1m6!3m5!1s0x2e6ff555ba54ddaf:0xdf0c1b2f117b776d!2sBbptu+ Hpt+Sapi+Perah!8m2!3d-

7.3062314!4d109.248507!3m4!1s0x2e6ff44fc3643a8d:0xa1679d6356d9f016!8m2!3d$\underline{7.3050244 ! 4 \mathrm{~d} 109.2483332}$ 


\subsection{Data Penelitian}

Data yang digunakan

1. Volume feses/kotoran Sapi Perah jenis Fries Holland

Tabel 1. Total jumlah Sapi dan jumlah feses yang dihasilkan

\begin{tabular}{|c|c|c|c|c|}
\hline No & Tempat & $\begin{array}{c}\text { Jumlah } \\
\text { Sapi (ekor) }\end{array}$ & $\begin{array}{c}\text { Jumlah } \\
\text { feses basah }(\mathrm{kg})\end{array}$ & $\begin{array}{c}\text { Jumlah } \\
\text { feses kering }(\mathrm{kg})\end{array}$ \\
\hline 1. & Free Stall 2 & 138 ekor & 4.140 & 2.070 \\
\hline 2. & Free Stall 3 & 94 ekor & 2.820 & 1.410 \\
\hline \multicolumn{3}{|c|}{ Total feses } & 6.960 & 3.480 \\
\hline
\end{tabular}

2. Gas yang dihasilkan

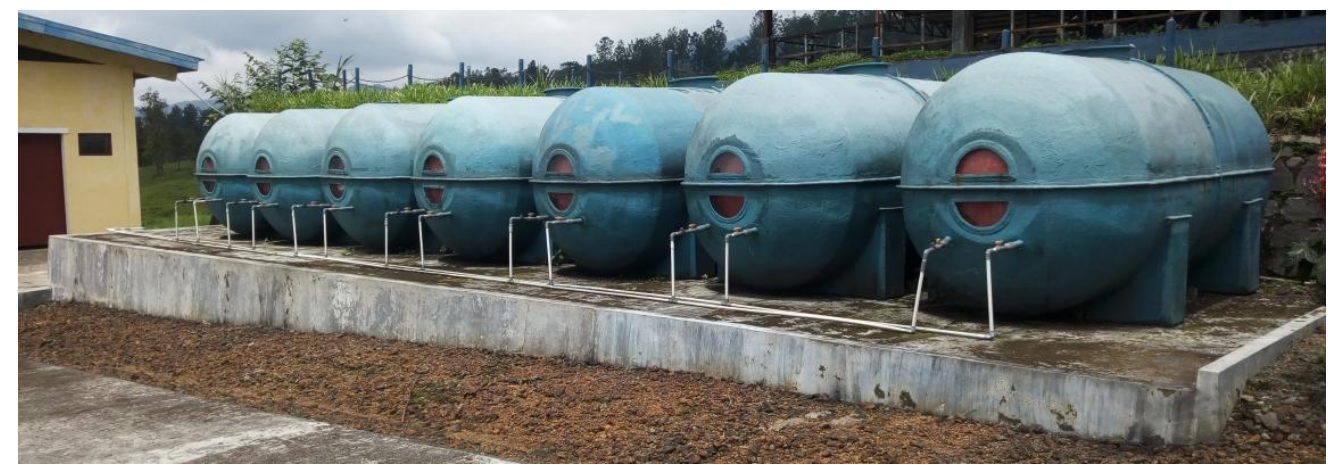

Gambar 3. Tabung Biogas

Masing-masing tabung memiliki volume $12 \mathrm{~m}^{3}$, sehingga total berjumlah $84 \mathrm{~m}^{3}$

3. Beban, dalam hal ini digunakan untuk penerangan/lampu, dengan rincian

Tabel 2. Komposisi daya yang disuplai oleh biogas

\begin{tabular}{clcccr}
\hline No & Nama Ruangan & Jenis lampu & Daya (watt) & Jumlah & Total Daya (watt) \\
\hline 1. & Ruang Genset & LED & 12 & 2 & 24 \\
2. & Free Stall 2 & LED & 12 & 7 & 84 \\
& & LHE & 26 & 1 & 26 \\
& & 8 & 1 & 8 \\
\multirow{2}{*}{ 3. Free Stall 3 } & Bohlam & 100 & 3 & 300 \\
& LHE & 45 & 7 & 315 \\
\hline \multicolumn{5}{c}{ Total keseluruhan daya } \\
\hline
\end{tabular}

\subsection{Analisa Data} $1 \mathrm{H}$.

Berdasarkan data yang sudah dihimpun berikut adalah analisis dengan menggunakan metode $5 \mathrm{~W}+$

Tabel 3. $5 \mathrm{~W}+1 \mathrm{H}$

\begin{tabular}{lll}
\hline $5 \mathrm{~W}+1 \mathrm{H}$ & \multicolumn{1}{c}{ Pertanyaan } & \multicolumn{1}{c}{ Jawaban } \\
\hline What & $\begin{array}{l}\text { Apa manfaat pembuatan biogas dari } \\
\text { feses Sapi }\end{array}$ & $\begin{array}{l}\text { Dapat mengurangi pencemaran udara, emisi gas } \\
\text { rumah kaca, dan pemanasan global karena feses }\end{array}$ \\
& & $\begin{array}{l}\text { Sapi yang mengandung gas metana tidak } \\
\text { dibiarkan menguap di udara tetapi dimasukkan } \\
\text { ke degester }\end{array}$ \\
& & $\begin{array}{l}\text { Pegawai BBPTU HPT Baturraden Area Farm } \\
\text { Who }\end{array}$ \\
& $\begin{array}{l}\text { Siapa yang mengkonsumsi energi listrik } \\
\text { yang dihasilkan dari biogas }\end{array}$ & $\begin{array}{l}\text { Limpakuwus di bagian kandang (Free Stall 2 } \\
\text { dan Free Stall 3) }\end{array}$
\end{tabular}

Techno Vol. 21, No. 1, April 2020: $21-28$ 


\begin{tabular}{lll}
\hline Why & $\begin{array}{l}\text { Mengapa energi listrik dari biogas baru } \\
\text { dapat digunakan untuk penerangan }\end{array}$ & $\begin{array}{l}\text { Karena harus ada pemantauan di bagian Genset, } \\
\text { disebabkan tegangan yang dihasilkan dapat naik } \\
\text { turun / fluktuatif }\end{array}$ \\
When & $\begin{array}{l}\text { Kapan energi listrik dari biogas dapat } \\
\text { digunakan }\end{array}$ & $\begin{array}{l}\text { Setiap saat, karena sumber energi (feses) yang } \\
\text { selalu ada }\end{array}$ \\
Where & Di mana energi listrik di munculkan & $\begin{array}{l}\text { Di Genset, dari gas metana konversi ke energi } \\
\text { listrik }\end{array}$ \\
How & $\begin{array}{l}\text { Bagaimana cara membangkitkan energi } \\
\text { listrik dari biogas }\end{array}$ & $\begin{array}{l}\text { Feses dari Sapi yang mengandung gas masuk ke } \\
\text { degester kemudian disaring dengan biogas } \\
\text { desulfurizer untuk didapatkan gas metana yang } \\
\text { lebih murni, kemudian masuk ke tabung } \\
\text { penampung dan setelah itu ke genset }\end{array}$ \\
\end{tabular}

Degester diisi dengan feses Sapi setiap pagi antara pukul 07.30-09.00 dan sore antara pukul 15.3016.30. Volume gas yang dihasilkan ditampung di tujuh tabung, 1 (satu) tabung volumenya $12 \mathrm{~m}^{3}$, kemudian lampu dihidupkan dari pukul 07.45-16.00, pengamatan dilakukan selama pagi hingga sore tujuannya untuk memudahkan dalam pengamatan.

\section{HASIL DAN PEMBAHASAN}

\subsection{Analisis Volume Feses / kotoran Sapi Perah Jenis Fries Holland (FH)}

BBPTU HPT Baturraden area limpakuwus terdapat 232 induk sapi yang digunakan untuk mensuplai biogas. Sapi jenis ini di Amerika disebut Holstein sedangkan di Eropa disebut Friesien. Sapi ini memiliki karakteristik

1. Warna bulunya belang hitam dan putih

2. Mempunyai sifat tenang dan jinak

3. Kepala panjang dan sempit dengan tanduk pendek dan menjurus ke depan, seperti pada gambar berikut :

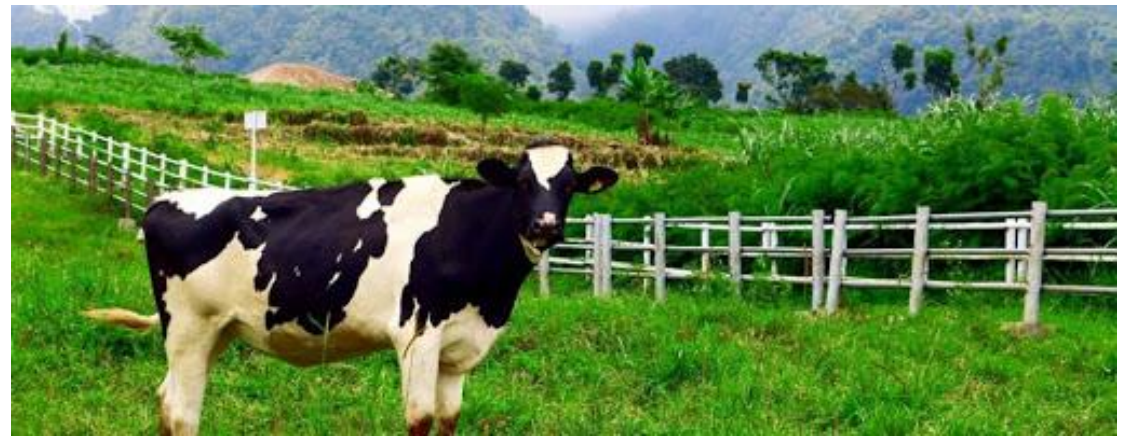

Gambar 4. Sapi FH (Friesiean Holstein)

Sumber : http://bbptusapiperah.ditjenpkh.pertanian.go.id/?m=201705

Dari kotoran $40 \mathrm{~kg}$ menghasilkan biogas $1,44 \mathrm{~m}^{3}$ [3]

Tabel 4. Jumlah biogas yang dapat dihasilkan

\begin{tabular}{rccr}
\hline No & Jumlah Sapi & Jumlah feses padat $(\mathrm{kg})$ & Biogas $\left(\mathrm{m}^{3}\right)$ \\
\hline 1. & 1 & 15 & 0,54 \\
2. & 232 & 6.960 & 125,28 \\
\hline
\end{tabular}

Satu Sapi dalam sehari menghasilkan 30 feses basah bila dikeringkan menghasilkan $15 \mathrm{~kg}$ feses padat setara dengan biogas $0,54 \mathrm{~m}^{3}$, sehingga dengan jumlah Sapi di free stall 2 dan 3 berjumlah 232 Sapi, maka dapat menghasilkan biogas $125,28 \mathrm{~m}^{3}$. 


\subsection{Analisis Gas yang Dihasilkan}

Gas yang dihasilkan oleh sapi dapat digunakan sebagai biogas karena mengandung gas metana $\left(\mathrm{CH}_{4}\right)$ dengan presentase yang dominan.

\begin{tabular}{cll}
\multicolumn{3}{c}{ Tabel 5. Komponen penyusun biogas } \\
\hline No & Jenis Gas & Jumlah $(\%)$ \\
\hline 1. & Metana & $54-70$ \\
2. & Karbondioksida & $27-45$ \\
3. & Air & 0,3 \\
4. & Hidrogen Sulfide & $0-3$ \\
5. & Nitrogen & $0,5-3$ \\
6. & Hidrogen & $5-10$ \\
\hline
\end{tabular}

Sumber : Pusat informasi dokumentasi PTP-ITB

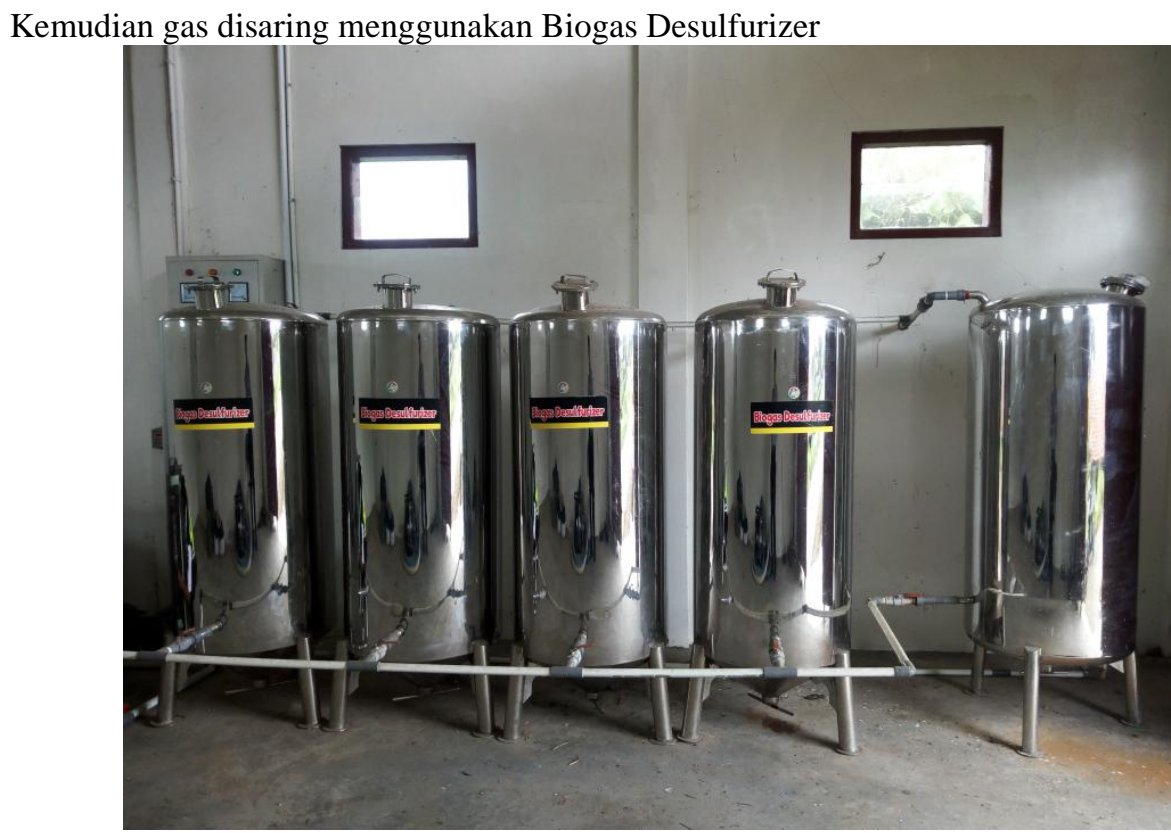

Gambar 5. Biogas Desulfurizer

Setalah disaring kemudian gas masuk ke tabung penyimpanan gas, seperti terlihat di Gambar 2, gas siap masuk ke genset. Dari genset terhubung ke beban, yang ditunjukkan pada tabel 2. Dengan beban 773 watt yang dinyalakan terus menerus selama 7 jam akan menghabiskan 1 tabung.

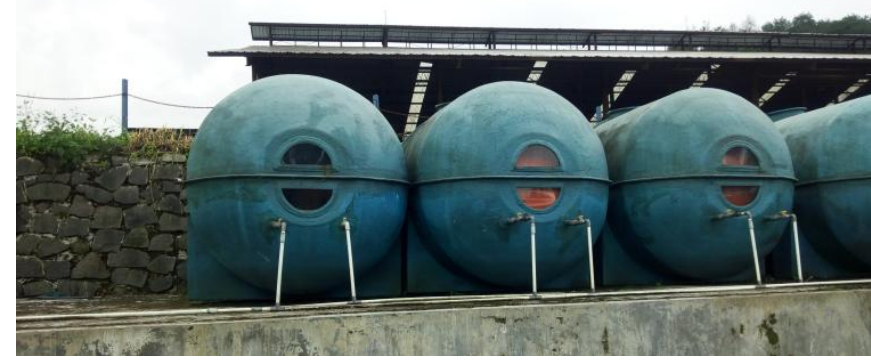

Gambar 6. Satu tabung biogas yang habis

\section{KESIMPULAN}

Dari penelitian ini dapat disimpulkan bahwa feses/kotoran sapi dalam hal ini jenis FH (Fries Holland/ Friesien Holstein) dapat digunakan sebagai biogas. Dari jumlah Sapi yang ada berjumlah 232 ekor dihasilkan feses basah $6.960 \mathrm{~kg}$, yang berarti feses keringnya adalah setengah dari feses basah yaitu $3.480 \mathrm{~kg}$. 
Dari 6.960 feses basah dihasilkan 125,28 $\mathrm{m}^{3}$ biogas yang ditampung di tabung penampung berjumlah tujuh, bisa dikonversi ke energi listrik sebesar 8.070,12 Watt. Energi listrik yang dihasilkan digunakan untuk beban berupa lampu/penerangan dengan total daya 773 watt, menghabiskan 1 tabung $\left(12 \mathrm{~m}^{3}\right)$ dalam waktu 7 jam.

\section{UCAPAN TERIMAKASIH}

Atas terselenggaranya penelitian ini, peneliti mengucapkan terima kasih kepada

1. LPPM UMP yang telah mendanai penelitian ini.

2. Segenap Pimpinan dan Karyawan BBPTU HPT Baturraden yang telah mengizinkan dan membantu peneliti dalam melakukan penelitian ini.

\section{DAFTAR PUSTAKA}

[1] Finahari, Ida N.,Djati HS.,dan Heni Susiati.,"Gas $\mathrm{CO}_{2}$ dan Polutan Radioaktif dari PLTU Batubara,"Jurnal Pengembangan Energi Nuklir Vol. 9 No.1,Juni 2007.

[2] https://id.wikipedia.org/wiki/Biogas

[3] Dianawati, Meksy. Mulijanti, Siti Lia.,” Peluang Pengembangan Biogas di Sentra Sapi Perah,” J. Litbang Pert. Vol. 34 No. 3 September 2015: 125-134

[4] Sanjaya, Denta. Agus Haryanto., Tamrin., " Biogas Production from A Mixture of Cow Manure with Chicken Manure," Journal of Power Electronics, vol. 10, pp. 65-71, 2010.

[5] Afrian. Chandra, et al., "Produksi Biogas dari Campuran Kotoran Sapi dengan Rumput Gajah (Pennisetum Purpureum)," 2017 Jurnal Teknik Pertanian Lampung-Vol. 6, No. 1: 21-32.

[6] Dewi, Rani Puspita., dan Kholik, Muhammad., "Kajian Potensi Pemanfaatan Biogas sebagai salah satu Sumber Energi Alternatif di Wilayah Magelang,"Journal of Mechanical Engineering, Vol. 2, No. 1, p-ISSN: 2598-7380 eISSN: 2613-9847. Maret 2018.

[7] Oktavia. Indri, dan Adi Firmansyah.."Pemanfaatan Teknologi Biogas sebagai Sumber Bahan Bakar Alternatif di Sekitar Wilayah Operasional PT. Pertamina EP Asset 2 Prabumulih Field," Jurnal CARE Jurnal Resolusi Konflik, CSR, dan Pemberdayaan Juni 2016, Vol. 1 (1): 32-36 ISSN: 2528-0848.

[8] Octaviani, Nilam Sari., and Semin.,"Technical Overview of Biogas Utilization as Fuel of Boat Engine," International Journal of Marine Engineering Innovation and Research, Vol. 2(2), Mar. 2018. 171-175 (pISSN: 2541-5972, eISSN: 2548-1479.

[9] Sulistiyanti. Y.et al'Pemanfaatan Kotoran Sapi sebagai Sumber Biogas Rumah Tangga di Kabupaten Pulang Pisau Provinsi Kalimantan Tengah," Jurnal Udayana Mengabdi, Volume 15 Nomor 2, Mei 2016

[10] Putri, Agung Intan, et al.,"Pengaruh Jenis Kotoran Ternak terhadap Kuantitas Biogas Jurnal Kesehatan Lingkungan” ]Vol.4, Mei 2014 : 45-49

[11] Ritonga, Abdul Mukhlis.,dan Masrukhi.,"Optimasi Kandungan Metana (CH4) Biogas Kotoran Sapi menggunakan berbagai Jenis Adsorben,"Rona Teknik Pertanian, 10(2) Oktober 2017.

[12] A.D Burke. 2001. Dairy Waste Anaerobic Digestion Handbook. Environmental Energi Company : Olympia.

[13] Hasiholan, Ucok.,Agus Haryanto.,dan Sigit Prabawa.,"Produksi Biogas dari Umbi Singkong dengan Kotoran Sapi sebagai Starter,’Jurnal Teknik Pertanian Lampung Vol.5, No. 2: 109-116,2016. 
Techno Vol. 21, No. 1, April 2020: 21-28 